\title{
CYBERCRIME: INTERNET DRIVEN ILLICIT ACTIVITIES AND BEHAVIOR
}

\author{
Maurice DAWSON \\ Illinois Institute of Technology, Chicago, United States of America \\ mdawson2@iit.edu
}

\begin{abstract}
Cybercrime affects multiple areas of society with nefarious activities ranging from human trafficking to illegal arms sale. The Internet has allowed some nefarious activities to be revived as others have emerged in this new age. In turn, this has become a national security issue for countries as this requires resources to combat this evolving threat. These activities include undermining legitimate services that provide government services to its citizens, such as passport, national identification, tax services, and more. This paper introduces some of these activities, enabling readers to understand this digital criminal world further.
\end{abstract}

KEYWORDS: cybercrime, human trafficking, dark web, online marketplace, cryptocurrency, disinformation

\section{Introduction}

The Internet has allowed for many technological advances that have brought forth positive outcomes. In retrospect, the Internet has also allowed for criminal activities to flourish. And while both positive and negative effects are expected, the use of the Internet by a criminal organization, nation-states, terrorists, extremists, and others finds another means to market their illegal activity. As the introduction of the technological phenomenon is no longer seen as a luxury but rather a basic need in some parts of the world (Reglitz, 2020; Greenwood, 2013). However, some nations heavily regulate Internet activities under the umbrella for terrorism, maintaining a political stronghold, censorship, or enforcement of that country's religious laws (Ayalew, 2019; Deibert, 2009). A handful of nations have been known to engage in censorship, such as China, Iran, and Saudia Arabia, to name a few (Deibert, 2009). Meanwhile, more countries have been known to use the Internet to target political dissidents such as Cuba, Ethiopia, Eritrea, Gambia, Morocco, North Korea, Russia, and more (Committee to Protect Journalists, 2020). Even with this mentioned censorship and oversight, illicit activities remain on the rise through the Internet.

In recent years, police and other law enforcement organizations have shut down pages that advocate prostitution. Originally websites such as Craiglist were known for the infamous ads that asked for donations in exchange for time (Hemmingson, 2008). This was the beginning of a new age for sex work, which took prostitution off the streets and created an atmosphere where the buyer could purchase a wanted service online (Cunningham \& Kendall, 2011). From Craigslist, Backpage became the new marketplace for sex with a sophistication, unlike others. Sites alike followed to assist 
in identifying law enforcement masquerading as prostitutes to warm others before they finalized an arrangement. This included keywords, emojis, and code talk that avoided communicating in a manner that didn't incriminate them. Other measures that modern computing platforms had using cloud services that were used as an untraceable telephone, voicemail, and text messaging. Previously, a telephone number could be used to identify a person. Still, with Google Voice services, this allowed people to create an email and cloud-based telephone service to avoid using their actual provider. And if confronted by law enforcement, it was easier to hide the number with removing the application or now having the cloud service forward the call to their phone. In turn, this made it challenging for law enforcement entities to use that as a sure means to locate the person providing services as now individuals could screen potential customers.

\section{Human Trafficking}

Websites such as Backpage was not only known for prostitution but human trafficking. Encrypted currency such as Bitcoin has allowed for illegal transactions of human sales to remain undetected and nearly untraceable (Portnoff, Huang, Doerfler, Afroz, \& McCoy, 2017). And even when the Federal Bureau took down Backpage for Investigation (FBI) shortly after similarly named sites popped up. Thus taking down the page served only as a quick win as one can use cached pages and repost information used previously.

For those involved in more sophisticated methods, the Dark Web remains the best avenue to stay undetected. As hyperconnected systems create a unique problem solving this matter becomes complex (Martinez, 2019). This means when you have multiple social media pages, Internet of Things (IoT) devices, public information, and data revealed through breaches, it allows someone to become a target through careful analysis of that information. Unprotected and uncontrolled data enable an attacker to target entities through careful selection (Martinez \& Dawson, 2019).

Social media pages such as Facebook, Instagram, Twitter, and others create an environment that enables personalized social engineering (Stewart \& Dawson, 2018). Information such as a birth month, home address, location, and even a public network allows an attacker to begin working on exploitation techniques. These can be in the form of someone carefully selecting a target to a third party having access to the account through a developed application in which you have granted rights to your information to use it. Researchers have looked at what factors lead to gullibility in an individual faced with social engineering threats based on personality traits. For human trafficking, it has been uncovered that some tactics are through the promise of work overseas with the hopes of escape from an oppressive or dangerous environment.

\section{Online Marketplace}

While human tracking has mostly moved to the Internet, so has other illicit activities such as the purchase of narcotics, government documents such as United States of America (USA) driver licenses, passports from multiple countries, and services such as contract killers. Former sites such as the Silk Road served as a crypto market for illegal drug trading until it was closed two years later (Maddox, Barratt, Allen, \& Lenton, 2016). Since Silk Road has been taken down, numerous pages have taken its place. And the problem with shutting down the operations on these pages is that the Dark Web consists of unindexed pages that are not found using an everyday browser such as Firefox, Chrome, or Internet Explorer. To even access these pages, The Onion Router (Tor) is required. Figure no. 1 displays a screenshot of an 
onion page accessed with the Tor Browser using Hidden Wiki to locate the page. The Hidden Wiki serves as a guide to pages on the Dark Web to be accessed, describing its service (Sinha, 2017).

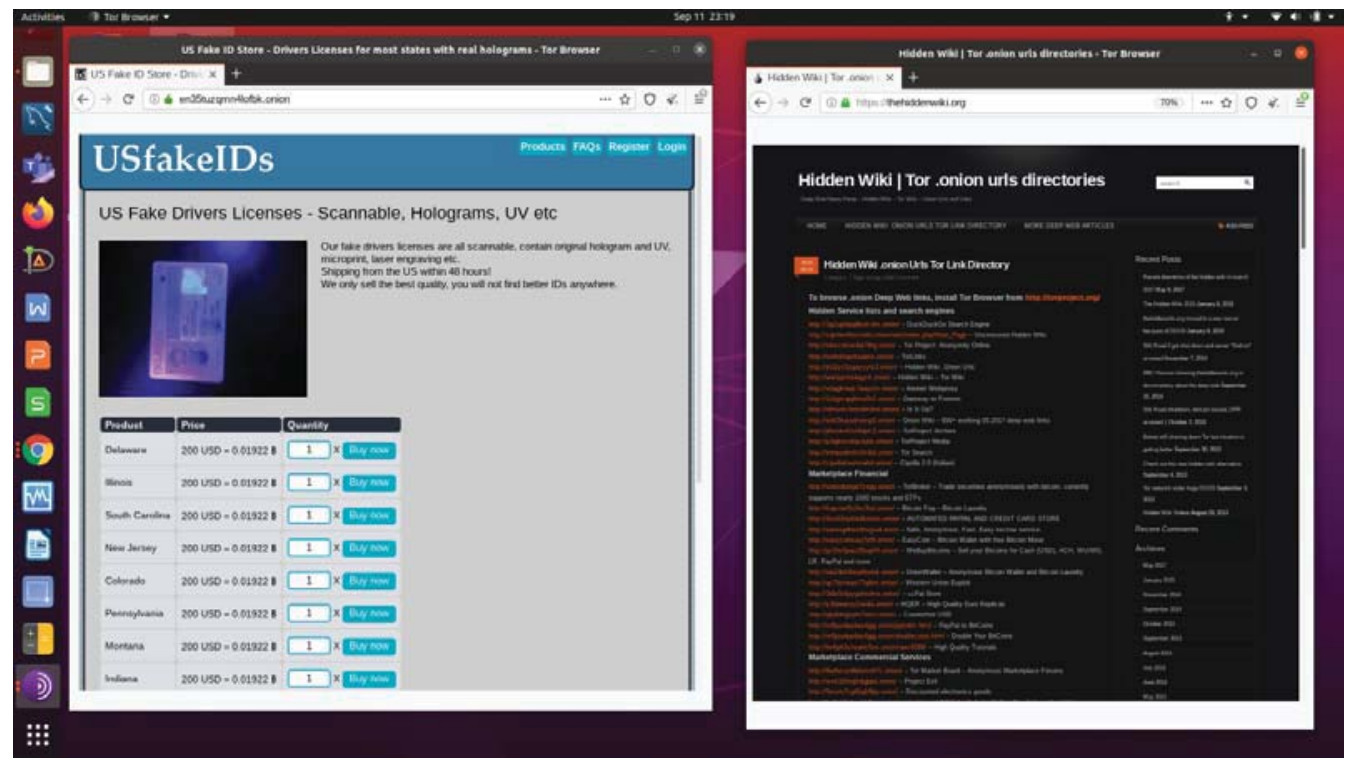

Figure no. 1: Example of Online Marketplace on Dark Web

Sites such as USfakeIDs provide their customers to purchase a driver's license from any state. These licenses are advertised as being near authentic to including the hologram. This site could serve underage teens in the purchase of alcohol, illegal's who require proper documentation, or individuals who seek something much more sinister as maintaining an identity to plan a terrorist attack. Other items sold are passport, birth documents, and other government-provided documents that are used to establish an identity on similar sites.

While the Hidden Wiki is not allinclusive, it does provide a starting point for those getting familiarized with the shadowy marketplace. Some sites that provide auctions and other services require Bitcoin payment before giving the actual onion link. This action is to show a real desire to participate rather than just browsing a storefront of illegal services and goods.

\section{Navigating the Dark Web}

The Dark Web requires Tor Browser to be installed on the system. While installing the browser allows someone to be safe, the other issues remain around the privacy of an Internet Service Provider (ISP) viewing activities. So the installation and the use of additional services of Virtual Private Network (VPN), encryption, and other security tools to altogether cloak activities. If the user uses Ubuntu or another Debian based Linux distribution, then installing the necessary Personal Package Archives (PPAs) must be done through the Command Line Interface (CLI). After that typing, the below installs and runs Tor.

\section{sudo apt update}

sudo apt install torbrowser-launcher 
And once Tor Browser is installed, then in the CLI typing torbrowser-launcher will launch Tor. If you navigate to show the application, then one could locate the application as well. Operating Systems (OS) such as Kali Linux and Tails have a number of these applications prebuilt. These OSs can do more than navigating the Dark Web while others are developed with digital crime and cyber warfare (Dawson \& Omar, 2015).

\section{Online Forums}

Countries have laws in place to protect and provide rights, such as freedom of speech. Therefore online forums provide a medium where people can freely share how they feel with likewise people. However, alt-right groups, nationalists, and domestic terrorist groups use them routinely to spread violence and hatred filled messages. In 2019, sites such as 8chan were removed from their host provider as three separate white nationalist groups posted manifestos in the forum. Pages such as 4chan and Reddit still have subthreads such as $\mathrm{r} / \mathrm{pol}$, banned. These pages are used to spread disinformation, propaganda and incite violent behaviors. In social media pages, it was uncovered that Russia controlled one of the largest Black Lives Matters (BLM) groups and used the Internet to further create a racial divide among Americans (Jamieson, 2020; Johnson, 2019). The website 4chan has banned the politically incorrect thread on the message board that could be found using https://boards.4chan.org/pol/ in the address bar.
Other forums may not give into online disinformation or spread hate but instead, inform those on how to obtain information for a service or good that may be deemed illegal. With gun crime high in some US cities, law enforcement must be able to track down firearms that are used in crimes. With 3D printed guns and gun parts, anyone can manufacture unlicensed and untraceable weapons. One such 3D gun that started this discussion was the Liberator gun (Walther, 2015). The federal government moved swiftly to have the file removed from the web, but hundreds of downloads occurred before this happens. Since then, the file has been shared on selected channels and still available today.

When discussing human trafficking, sex work is one area where women and children are trafficked into where they work under the cloak of a legitimate business. Massage parlors have been known to traffic people illegally. One particular site, rubmaps, served as a forum for massage parlors and provided detailed reviews. This site offered detailed reviews and mapped directly to the active or inactive massage parlor. This particular site uses a .ch domain as numerous others to avoid being shut down by the US government. This allows a site to operate outside the legal jurisdiction of the US. Figure no 2 shows the amount of detail provided from ethnicity to which provider does what service. Other details include operating hours, payment accepted, and if business accommodates semi-trucker. 
Massage \& Spa in Chicago, Illinois

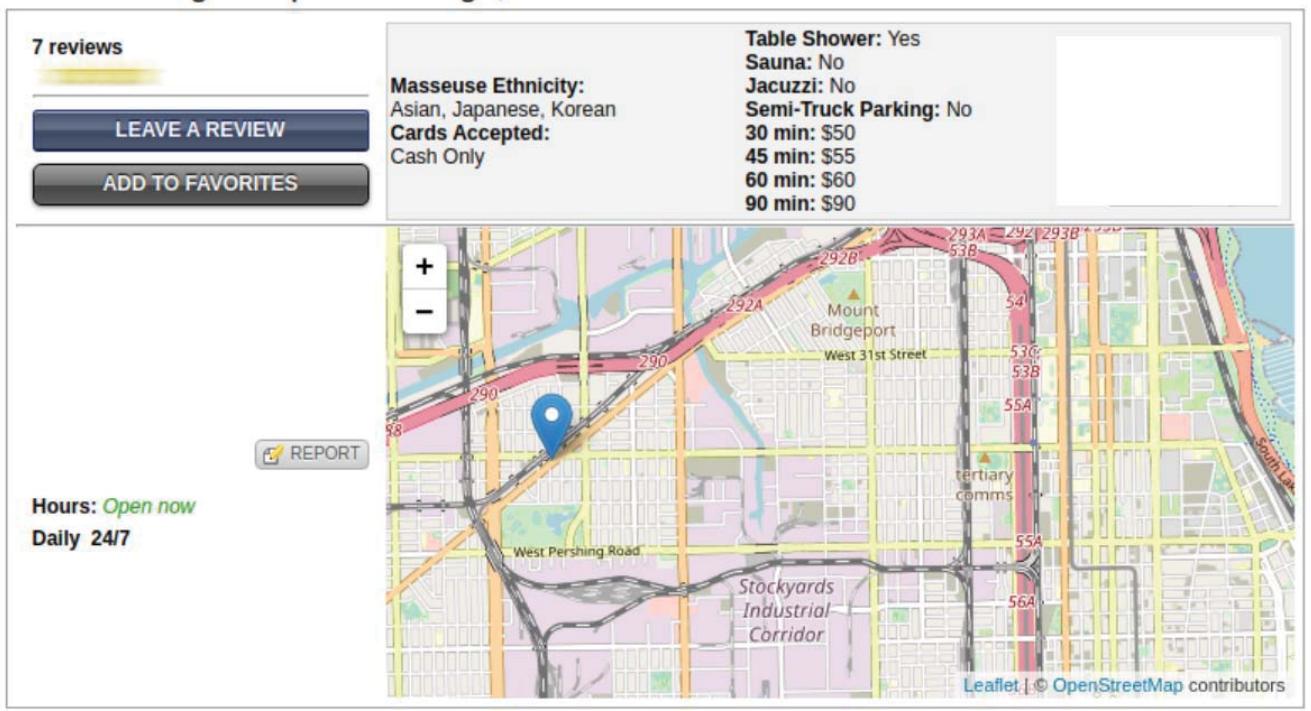

Figure no 2: Example of Rubmaps Massage Review

\section{Cryptocurrencies and Blockchain}

In recent years, cryptocurrency has been the rave, but that has been surrounding the exploding growth in Bitcoin's value. There are only aspirations and hopes of regulating cryptocurrencies (Narayanan, Bonneau, Felten, Miller, \& Goldfeder, 2016). In the meantime, this form of payment for the exchange of illegal goods and services. One researcher takes an in-depth look into Bitcoin money laundering, exploring the negatives and positive outcomes of using cryptocurrency (Bryans, 2014).

Even though the hype is dying down around cryptocurrency, this is still the currency of choice to evade law enforcement (Wolfson, 2018). Among the largest unregulated markets in the world are cryptocurrencies. Researchers estimate approximately $\$ 76$ billion of illegal activities per year, with one-quarter of Bitcoin users involved (Foley, Karlsen, \& Putninšs, 2019). These numbers are astronomical and transforming the known black markets by enabling new e-commerce.
There has been a movement to trace criminal activity across the Bitcoin blockchain. By examining the blockchain activity through a process called clustering, discovering accounts purpose uncovers what type of storefront it is linked to. For example, if an account is used to make purchases on a Dark Web marketplace, we can begin pinpoint appearances tied to the same Bitcoin wallet. This action may mean the same entity also controls them. Once that entity becomes known, then analysis can be done to begin uncovering who that entity is through methods such as Open Source Intelligence (OSINT) and other forms of intelligence analysis coupled with data-driven tools.

\section{Conclusions}

The activities that were once considered in the shadows over the years were brought into the light. For a moment, law enforcement agencies globally were able to, at the least, understand what needed to be done and begin to use resources to combat these issues. With the emergence of the Dark Web, and cryptocurrencies 
Internet-driven illicit activities have a refuge. To combat this problem, sufficient resources must be made available. Another action is educating people early enough to become aware of safe and secure Internet use to minimize the risk and exposure associated with their Personal Identifiable Information (PII). When individuals know how to properly lock down their pages and understand how to limit their threat landscape, it will be more difficult for predators to prey upon them.

Bad actors have shown the ability to quickly move people and goods largely undetected shows multiple holes in a supply chain, policing, and detecting abnormalities in a more extensive system that is built to protect its citizens. But with online websites that provide access to prostitution, a lack of checks makes it easier to traffic women and children. With the widespread engagement in social media, disinformation nationstates and others alike can influence massive crowds. Through the use of cryptocurrencies, the funds used for illegal activities become difficult to track. Internetdriven illicit activities can undermine what governments have set up to build confidence among its citizens to include circumventing established laws.

\section{REFERENCES}

Ayalew, Y. E. (2019). The Internet shutdown muzzle (s) freedom of expression in Ethiopia: competing narratives. Information \& Communications Technology Law, Vol. 28, Issue 2, 208-224.

Bryans, D. (2014). Bitcoin and money laundering: mining for an effective solution. Indiana Law Journal, Vol. 89, Issue 1, 441.

Committee to Protect Journalists. (2020). 10 Most Censored Countries, available at: https://cpj.org/reports/2019/09/10-most-censored-eritrea-north-korea-turkmenistan-journalist/, accessed on 12 September 2020.

Cunningham, S., \& Kendall, T. D. (2011). Prostitution 2.0: The changing face of sex work. Journal of Urban Economics, Vol. 69, Issue 3, 273-287.

Dawson, M., \& Omar, M. (2015). New Threats and Countermeasures in Digital Crime and Cyber Terrorism. Hershey PA, USA: IGI Global.

Deibert, R. J. (2009). The geopolitics of internet control: Censorship, sovereignty, and cyberspace. In Chadwick, A., \& Howard, P.N., Routledge handbook of Internet Politics (323-336). London, UK: Routledge Handbooks.

Foley, S., Karlsen, J. R., \& Putninšs, T. J. (2019). Sex, drugs, and bitcoin: How much illegal activity is financed through cryptocurrencies?. The Review of Financial Studies, Vol. 32, Issue 5, 1798-1853.

Greenwood, F. (2013). Internet access is "essential” human right, rules German court, available at: https://www.pri.org/stories/2013-01-28/internet-access-essential-human-rightrules-german-court, accessed on 12 September 2020.

Hemmingson, M. (2008). Cyber-Hookers AKA Providers: Off the Street and onto Craigslist. SSRN Electronic Journal. http://dx.doi.org/10.2139/ssrn.1084415.

Jamieson, K. H. (2020). Cyberwar: how Russian hackers and trolls helped elect a president: what we don't, can't, and do know. New York, USA: Oxford University Press.

Johnson, D. E. (2019). Russian Election Interference and Race-Baiting. Columbia. Journal of Race and Law, Vol. 9, No. 2, 191.

Maddox, A., Barratt, M. J., Allen, M., \& Lenton, S. (2016). Constructive activism in the dark web: cryptomarkets and illicit drugs in the digital 'demimonde'. Information, Communication \& Society, Vol. 19, Issue 1, 111-126. 
Martínez, F. G. (2019). Special Problems in Information Security: from Privacy to Emerging Technologies for Hyperconnected Systems. Master Thesis, Universidad Politécnica de Madrid, Spain.

Martinez, F. G., \& Dawson, M. (2019). Unprotected Data: Review of Internet Enabled Psychological and Information Warfare. Land Forces Academy Review, Vol. XXIV, Issue 3(95), 187-198.

Narayanan, A., Bonneau, J., Felten, E., Miller, A., \& Goldfeder, S. (2016). Bitcoin and cryptocurrency technologies: a comprehensive introduction. Princeton University Press.

Portnoff, R. S., Huang, D. Y., Doerfler, P., Afroz, S., \& McCoy, D. (2017). Backpage and bitcoin: Uncovering human traffickers. In Proceedings of the $23^{\text {rd }}$ ACM SIGKDD International Conference on Knowledge Discovery and Data Mining (pp. 1595-1604).

Reglitz, M. (2020). The Human Right to Free Internet Access. Journal of Applied Philosophy, Vol. 37, Issue 2, 314-331.

Sinha, S. (2017). Dark Web and Tor. In Beginning Ethical Hacking with Python (pp. 173-177). Berkeley, CA: Apress.

Stewart, J., \& Dawson, M. (2018). How the modification of personality traits leave one vulnerable to manipulation in social engineering. International Journal of Information Privacy, Security and Integrity, Vol. 3, Issue 3, 187-208.

Walther, G. (2015). Printing insecurity? The security implications of 3d-printing of weapons. Science and engineering ethics, Vol. 21, Issue 6, 1435-1445.

Wolfson, R. (2018). Tracing Illegal Activity through the Bitcoin Blockchain to Combat Cryptocurrency-Related Crimes, available at: https://www.forbes.com/sites/ rachelwolfson/2018/11/26/tracing-illegal-activity-through-the-bitcoin-blockchain-to-combatcryptocurrency-related-crimes/, accessed on 12 September 2020. 